\title{
A HIDDEN PRESSURE GRADIENT THAT CAN BE EASILY PASSED OVER IN PROSTHETIC MITRAL VALVE
}

\author{
SE-JUNG YOON, MD ${ }^{1}$, EUI-YOUNG CHOI, MD², SUNG-AI KIM, MD², CHI-YOUNG SHIM, MD², \\ JONG-WON HA, MD, PHD ${ }^{2}$, SE-JOONG RIM, MD, PHD² AND NAMSIK CHUNG, MD, PHD ${ }^{2}$ \\ ${ }^{1}$ DIVISION OF CARDIOLOGY, NHIC ILSAN HOSPITAL, GOYANG, KOREA \\ ${ }^{2}$ DIVISION OF CARDIOLOGY, YONSEI CARDIOVASCULAR CENTER, YONSEI UNIVERSITY COLLEGE OF MEDICINE, SEOUL, KOREA
}

KEY WORDS : Prosthetic mitral valve · Doppler · Paravalvular leakage.

A fifty three-year-old woman was admitted to the hospital for aggravated dyspnea for two months. She has been performed double valve replacement (DVR) [omniscience \#29 for mitral valve (MV), \#19 for aortic valve (AV)] fourteen years ago due to rheumatic heart disease (mitral stenosis and aortic stenosis). The blood pressure was $90 / 60 \mathrm{mmHg}$ and pulse rate was $76 / \mathrm{min}$ and body temperature was $36.4^{\circ} \mathrm{C}$. The chest X-ray revealed marked cardiomegaly and prominent pulmonary vasculature and EKG revealed atrial fibrillation (90/min). There were pansystolic murmur in left parasternal and apical area and marked neck vein engorgement. Initially, the peak and mean pressure gradient (PG) of prosthetic aortic valve were 122 and $71 \mathrm{mmHg}$ and those of prosthetic mitral valve were 39.1 and $15.4 \mathrm{mmHg}$, respectively. (Fig. 1)

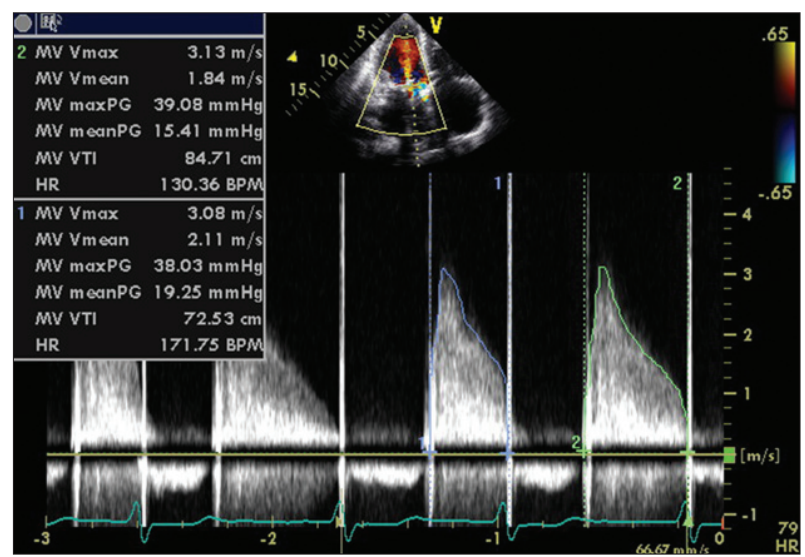

Fig. 1. Peak and mean pressure gradient of mitral inflow. Note the high peak PG across prosthetic mitral valve compared to mean PG. on transthoracic echocardiography (TTE). The right ventricular pressure (RVP) was unusually high, up to $99 \mathrm{mmHg}$ (Fig. 2), which has been within normal range in post operation. All of the measurements of pressure gradient were performed several times considering the rhythm of atrial fibrillation (four to six beats, each time on average). We therefore concluded that the main problem was the dysfunction of both prosthetic valves, which showed limitation of motion in fluoroscopic evaluation (both were tilting disc valves opening only to 30 degree) and resultant elevated LVEDP, LA pressure and RVP. However, there were a few points that could not be overlooked in this patient. First, the inappropriately severe pulmonary hypertension up to $99 \mathrm{mmHg}$, Second, high peak PG across prosthetic

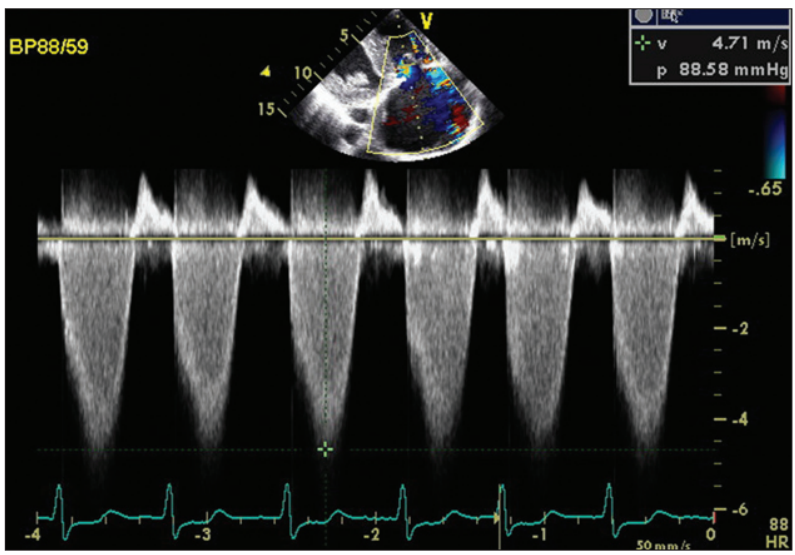

Fig. 2. Elevated right ventricular systolic pressure of $99 \mathrm{mmHg}$ assuming right atrial pressure of $10 \mathrm{mmHg}$. 


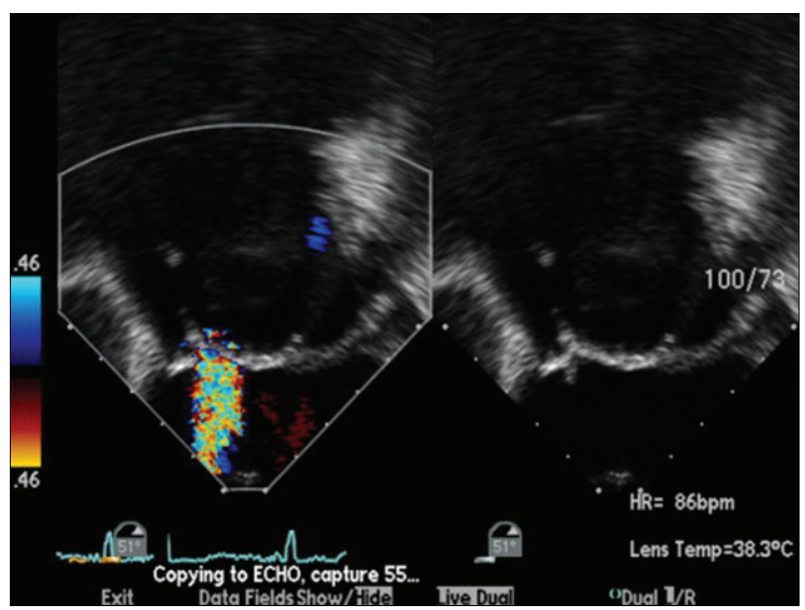

Fig. 3. Paravalvular leakage flow of prosthetic mitral valve on TEE $\left(51^{\circ}\right)$.

mitral valve compared to mean PG. We performed transesophageal echocardiography (TEE) for further evaluation and found another important factor of severe pulmonary hypertension which has been overlooked at the first time. There was a small paravalvular leakage in septal annulus of prosthetic MV (Fig. 3) and after repetitive measurement of the leakage flow, we could finally obtain the doppler image of PG across the leakage flow of mitral valve, which showed very high peak systolic PG as much as $180 \mathrm{mmHg}$ (Fig. 4). Considering the systemic blood pressure $(90 / 60 \mathrm{mmHg}$ ) and PG across both valves from doppler echocardiography (peak systolic PG across the aortic valve; $122 \mathrm{mmHg}$ and peak systolic PG across the mitral valve ; $180 \mathrm{mmHg}$ ), we could estimate the systolic LV pressure of $212 \mathrm{mmHg}$ and the LA pressure of $30 \mathrm{mmHg}$ and it corresponded well with mean pulmonary capillary wedge pressure (PCWP) from cardiac catheterization $(27 \mathrm{mmHg})$.

In reliable screening of mechanical prosthetic mitral valve dysfunction by TTE, the peak velocity of mitral inflow and ratio of time velocity integral in mitral inflow (TVIMv) to that in left ventricular outflow tract (TVILVot) were the best predictors of significant MR. ${ }^{122}$ In this patient, because both valves were replaced, TVILvot can not be used for predictor but the peak velocity of mitral inflow was useful index of MR. Paravalvular leakage is a frequent cause of

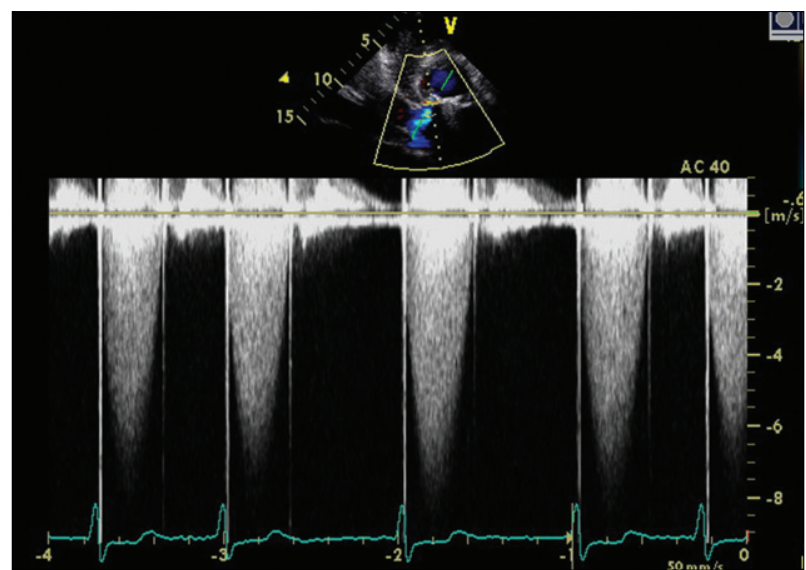

Fig. 4. The significant paravalvular leakage flow of prosthetic mitral valve (pressure gradient up to $180 \mathrm{mmHg}$ ).

reoperation after mitral valve replacement (MVR) occurring between 1.2 and $12.5 \%$ of MVR procedures. ${ }^{3)}$ Patients with paravalvular leakage with no severe symptoms can be treated conservatively and followed up. A more aggressive surgical treatment is recommended for patients with paravalvular leakage and severe anemia or heart failure. ${ }^{45)}$ We can confirm the usefulness of doppler echocardiography in understanding the causes and severity of pressure overloading status that can be easily overlooked in such as feeble of flow like paravalvular leakage. "Doppler" in echocardiography, gives much information and tells us the useful and exact data about hemodynamics.

\section{REFERENCES}

1. Olmos L, Salazar G, Barbetseas J, Quiñones MA, Zoghbi WA. Usefulness of transthoracic echocardiography in detecting significant prosthetic mitral valve regurgitation. Am J Cardiol 1999;83:199-205.

2. Fernandes V, Olmos L, Nagueh SF, Quiñones MA, Zoghbi WA. Peak early diastolic velocity rather than pressure half-time is the best index of mechanical prosthetic mitral valve function. Am J Cardiol 2002;89:70410.

3. Cicco GD, Russo C, Moreo A, Cesare Beghi, Fucci C, Gerometta P, Lorusso R. Mitral valve periprosthetic leakage: anatomical observations in 135 patients from a multicentre study. Eur J Cardiothorac Surg 2006; 30:887-91.

4. Jindani A, Neville EM, Venn G, Williams BT. Paraprosthetic leak: a complication of cardiac valve replacement. J Cardiovasc Surg 1991; 32:503-8.

5. Oh MK, Kim WS, Kim SY, Park JH, Kwon SO, Nah JC, Choi JW, Cho WH, Kim YI, Choi SK. A case of hemolytic anemia following mitral valve repair. J Cardiovasc Ultrasound 2007;15:63-5. 